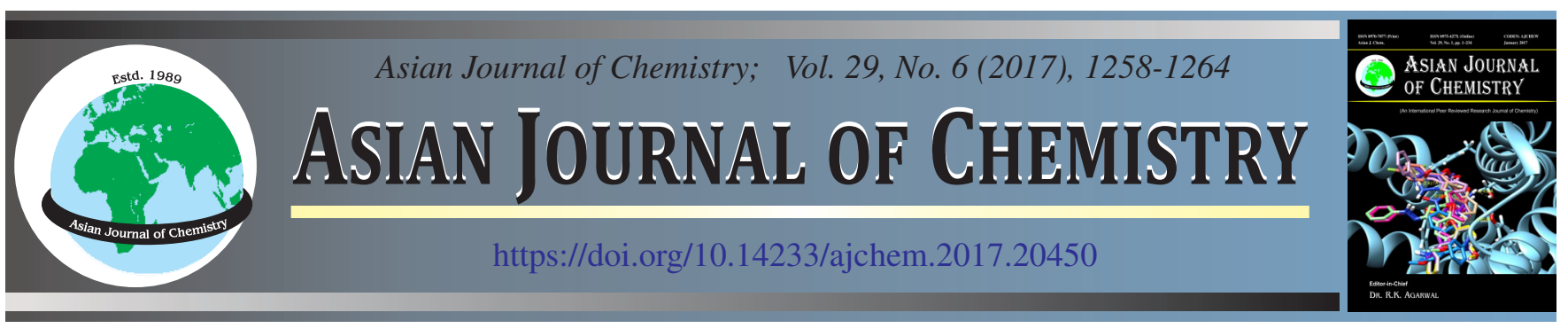

\title{
Removal of Procion Blue by Using Marsilea mutica Dead Biomass: Adsorption Kinetics and Equilibrium Studies
}

\author{
S. JEMIMAH ${ }^{1,2, *}$ and S.R. BHEETER ${ }^{2}$
}

${ }^{1}$ Department of Chemistry, St. Joseph's Institute of Technology, Chennai-600 119, India

${ }^{2}$ Department of Chemistry, St. Joseph's College (Autonomous), Tiruchirappalli-620 002, India

*Corresponding author: Fax: +91 44 24503133; Tel: +91 44 24503132; E-mail: jemimahraj@ gmail.com

\section{INTRODUCTION}

The availability of pure drinking water is one of our world's primary environmental concerns and the chief causative agent is contamination of available water resources. Among the many pollutants, textile, paper, rubber, plastic, cosmetic, pharmaceutical and food industries that use dyes and pigments are the main sources which produce dye effluent-rich wastewater, which are eventually allowed to mix with the drinking water resources. Principal portions of the annual production of dyes are azo and reactive dyes. The use of various types of dyes and chemical substances during dyeing processes could be the cause for the change in industrial wastewater characteristics such as $\mathrm{pH}$, colour, chemical content and chemical oxygen demand (COD); and could cause significant disturbance of photosynthetic processes in surface waters [1]. Some researchers have used several techniques for the removal of dyes from aqueous solutions such as coagulation and flocculation, reverse osmosis, ozonation, ion exchange, photochemical thermal degradation, electrochemical techniques etc, which are very expensive [2]. Several adsorbents have also been experimented upon as potential sorbents for dye molecules for $e . g$. activated carbon from sources like wood [3], hazel nut [4,5], bagasse [6], coir pith [7], orange peel [8], coconut shell
[9], tobacco stem [10] and other dead biomass resources. Activated carbons are the most widely used adsorbents because they have an excellent adsorption capability for organic molecules, but their main disadvantage is their high cost. So there is huge demand for cheaper, effective and eco-friendly substitutes such as chitosan [11], agricultural wastes [11,12], clay [13] and other biosorbents.

Among the commonly used biosorbents, aquatic plants are one of the most potential, economical and easily available sources which has been proven to effectively remove dyes from aqueous solutions $[14,15]$. Water clover is a water plant, native to Australia with very attractive clover-like leaves that are either held above water or submerged. It grows in the edges of ponds and lagoons, on river banks and in deep water. The vigorous rhizomes of water clover allow it to spread quickly which in turn completely blocks sunlight, decreases oxygen levels thereby suffocating desirable aquatic life. Hence water clover dead biomass was chosen as a biosorbent for dye removal.

Procion blue H-5R is commonly used in hot water dyeing for fabric painting and printing. Procion blue H-5R belongs to a group of azo dyes which are known to be toxic to the environment [16]. Among the various techniques employed for dye removal from waste waters, biosorption has received special interest due to its economical, efficient and eco-friendly 
nature. In the present study the adsorption of procion blue $\mathrm{H}$ $5 \mathrm{R}$ onto water clover was investigated.

\section{EXPERIMENTAL}

Water clover plants, botanically called as Marsilea mutica were collected in a local pond in Chennai, India, washed with tap water and then with deionized water. The plants inclusive of leaves, stem and roots were sun-dried, ground using a domestic mixie and sieved to get particles in the size of 70-80 mesh. Procion blue $\mathrm{H}-5 \mathrm{R}$ also called as cibacron blue $2 \mathrm{R}$ or reactive blue 13 (C.I. No. 181575, m.f.: $\mathrm{C}_{29} \mathrm{H}_{16} \mathrm{~N}_{7} \mathrm{O}_{14} \mathrm{Na}_{4} \mathrm{~S}_{4} \mathrm{Cl}$, m.w.: 866.06 and $\lambda_{\max }: 444 \mathrm{~nm}$ ) was purchased from Alfa Aesar and used as an adsorbate without purification prior to use. For the preparation of all the solutions double distilled water was used. $10,000 \mathrm{mg} / \mathrm{L}$ of procion blue $\mathrm{H}-5 \mathrm{R}$ dye was prepared as a stock solution in a standard flask. The desired concentrations for various experiments were obtained by successive dilution. The chemical structure of the dye is shown in Fig. 1. Sodium hydroxide and hydrochloric acid used for $\mathrm{pH}$ studies were procured from Alfa Aesar and were of analytical grade. $0.1 \mathrm{~N}$ solutions of $\mathrm{NaOH}$ and $\mathrm{HCl}$ were used to maintain the required $\mathrm{pH}$. Concentration of unadsorbed dye in aqueous solution was measured using UV-visible spectrophotometer (Hitachi, U3210, Japan). FT-IR, used for the determination of functional groups on the water clover surface was recorded using a Thermo IS5 FT-IR spectrophotometer. The dried biomass was ground well with $\mathrm{KBr}$ and compressed to form a pellet to obtain an absorption spectrum in the range of $4000-400 \mathrm{~cm}^{-1}$. Scanning electron microscope was used to elucidate the surface morphology of water clover before and after adsorption of the dye molecules. SEM-EDS was recorded using Hitachi $3000 \mathrm{H}$ SEM, which was operated at an accelera-ting voltage of 5-10 $\mathrm{kV}$.<smiles></smiles>

Fig. 1. Chemical structure of procion blue H-5R

Batch adsorption studies: Batch studies were conducted to find the optimum operating conditions for the adsorption of procion blue $\mathrm{H}-5 \mathrm{R}$ dye present in aqueous solution using biosorbent water clover. Adsorption experiments were initiated by placing a known quantity of water clover and $50 \mathrm{~mL}$ of the prepared procion blue $\mathrm{H}-5 \mathrm{R}$ dye solution into $250 \mathrm{~mL}$ Erlenmeyer flasks. The water clover sorbent loading was varied between 0.1 and $0.5 \mathrm{~g}$ and initial concentration between 25 and $200 \mathrm{mg} / \mathrm{L}$. For analysis in the linear Beer-Lambert region, the concentrated solutions were suitably diluted. The flask was placed in an orbital shaker, which was held constant at a revolution of 180 cycles $\mathrm{min}^{-1}$. Dye concentrations in the supernatant solutions were estimated at regular time intervals of $15,30,60,90,120,150,180$ and $210 \mathrm{~min}$ by measuring the absorbance at maximum wavelengths of dyes. The equilibrium adsorption capacities $\left(\mathrm{q}_{\mathrm{eq}}\right)$ at different solute concentrations were determined according to mass balance of the adsorbate.

$$
\mathrm{q}_{\mathrm{eq}}=\frac{\left(\mathrm{C}_{0}-\mathrm{C}_{\mathrm{eq}}\right) \mathrm{V}}{\mathrm{M}}
$$

where $\mathrm{C}_{\mathrm{o}}$ and $\mathrm{C}_{\mathrm{eq}}$ are the initial and equilibrium concentrations of the dye $\left(\mathrm{mg} \mathrm{L}^{-1}\right)$, respectively, $\mathrm{V}$ is the volume of the aqueous solution (L) and $\mathrm{M}$ is the mass of biosorbent used $(\mathrm{g})$ in the adsorption. The $\mathrm{pH}$ of the solution was varied from 1-6 using $\mathrm{HCl}$ or $\mathrm{NaOH}$ depending upon the required $\mathrm{pH}$.

Adsorption kinetics: The study of adsorption dynamics describes the rate of dye uptake and evidently this rate controls the residence time of adsorbate uptake at the sorbent-solution interface. The kinetics of procion blue $\mathrm{H}-5 \mathrm{R}$ dye adsorption on water clover was analyzed using pseudo first-order and pseudo second-order kinetic models. The correlation co-efficient $\left(\mathrm{R}^{2}\right)$ expresses the agreement between experimental data and the model expected values. $50 \mathrm{~mL}$ of procion blue $\mathrm{H}-5 \mathrm{R}$ solution of different concentrations between $25-200 \mathrm{mg} / \mathrm{L}$ were taken in separate Erlenmeyer flasks. The adsorbent of $75 \mathrm{~mm}$ mesh size and dosage of $0.1 \mathrm{~g}$ was transferred into each of the flasks and kept in an orbital shaker. Samples were withdrawn at regular time intervals from 0 to $210 \mathrm{~min}$, centrifuged, absorbance was measured and the equilibrium adsorption capacities were analyzed. The amount of adsorption at time $\mathrm{t}, \mathrm{q}_{\mathrm{t}}(\mathrm{mg} / \mathrm{g})$, was calculated by:

$$
\mathrm{q}_{\mathrm{t}}=\frac{\left(\mathrm{C}_{0}-\mathrm{C}_{\mathrm{t}}\right) \mathrm{V}}{\mathrm{M}}
$$

where $C_{o}$ and $C_{t}(m g / L)$ are the initial and at any time concentrations of the dye $\left(\mathrm{mg} \mathrm{L}^{-1}\right)$, respectively, $\mathrm{V}$ is the volume of the aqueous solution $(\mathrm{L})$ and $\mathrm{M}$ is the mass of dry adsorbent used $(\mathrm{g})$ in the adsorption.

\section{RESULTS AND DISCUSSION}

FT-IR analysis: The FT-IR spectrum obtained for biomass before and after procion blue $\mathrm{H}-5 \mathrm{R}$ dye adsorption process is shown in Fig. 2.

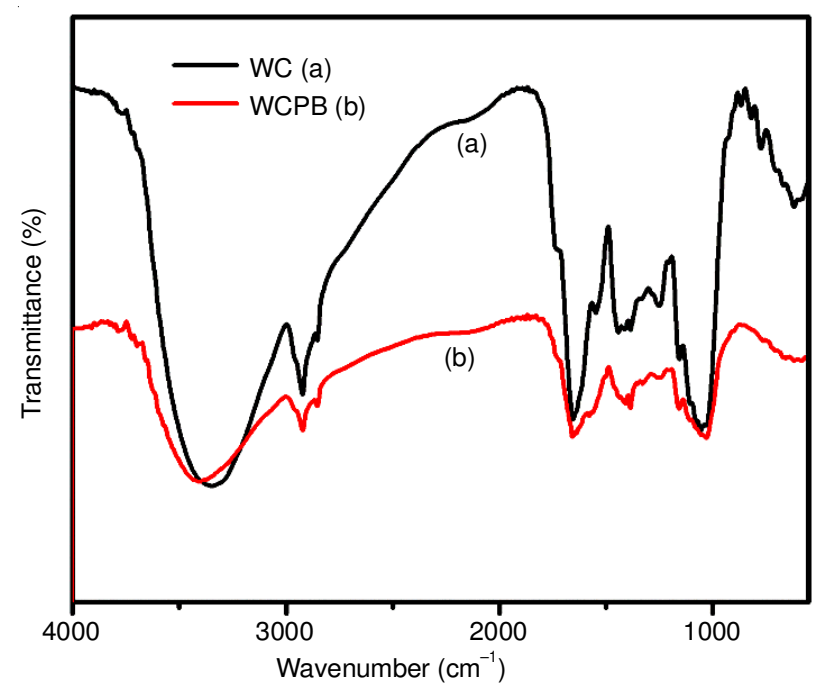

Fig. 2. FT-IR of water clover before (WC) and after adsorption of procion blue H-5R (WCPB) 
The FT-IR spectrum of water clover showed peaks at 3406 , 2921, 2852, 1656, 1407, 1384 and 1156 and $1029 \mathrm{~cm}^{-1}$ which may be assigned respectively to $\mathrm{OH}$ group, asymmetric $\mathrm{C}-\mathrm{H}$ stretching, $\mathrm{C}-\mathrm{H}$ stretch, carbonyl stretch, $\mathrm{P}=\mathrm{O}$ stretching, $\mathrm{CH}_{2}$ bend and $\mathrm{O}-\mathrm{H}$ bending vibration of phenolic and carboxylic groups. The intensities of the peaks decreased or slightly shifted in the case of dye-adsorbed water clover. Similar results were reported in previous work [17].

SEM and EDX analysis: The SEM analysis clearly indicates the presence of irregular and highly porous structure of water clover, which is attributed to be the major cause for providing more surface area of biosorbent thereby increasing the uptake capacity of the procion blue H-5R dye $[18,19]$. The micrograph of dye-loaded water clover biomass in Fig. 3 clearly shows small spherical dye molecules adsorbed on the surface of the biomass. EDAX spectra of water clover indicate the presence of the elements potassium, carbon, oxygen, sodium and chlorine. When the EDAX spectra of water clover before and after adsorption of procion blue H-5R were compared, the weight $\%$ of sodium and oxygen increased upon procion blue $\mathrm{H}-5 \mathrm{R}$ adsorption while the weight $\%$ of potassium and chlorine decreased after procion blue $\mathrm{H}-5 \mathrm{R}$ dye adsorption.

Effect of sorbent dosage: The effect of adsorbent dosage gives an idea of how a dye can be used in minimum doses so as to use the adsorbent in a cost-effective manner [20]. The effect of adsorbent dosage on procion blue $\mathrm{H}-5 \mathrm{R}$ adsorption by water clover is shown in Fig. 4. It can be seen that the adsorption capacity decreased with increase in adsorbent dosage. This shows that water clover is a superior sorbent at low dosage. The clustering of the adsorbent particles which may take place at higher levels of sorbent resulting in less utilization of available reactive sites could be a cause for this trend [21].

Effect of solution pH: $\mathrm{pH}$ is one of the most influencing parameters affecting aqueous chemistry, ionization of the dyes and surface binding sites of the adsorbents [22]. It has been reported that anions are more favourably adsorbed at lower $\mathrm{pH}$ values than cations whose adsorption is preferable at higher $\mathrm{pH}$ due to desorption of $\mathrm{OH}^{-}$ions on the surface [23,24]. This is evident in the present study, where procion blue H-5R, an anionic dye shows efficient adsorption onto water clover at lower $\mathrm{pH}$ values. The electrostatic interactions are diminished by increasing the solution acidity to an extent where the negative charge of the systems becomes negligible $[25,26]$. The effect of solution $\mathrm{pH}$ on the adsorption capacity of water clover was studied at $50 \mathrm{mg} / \mathrm{L}$ initial dye concentration and $0.1 \mathrm{~g}$ adsorbent dose. As shown in Fig. 5, the amount of adsorption at equilibrium of water clover was found to decrease with increase in $\mathrm{pH}$.
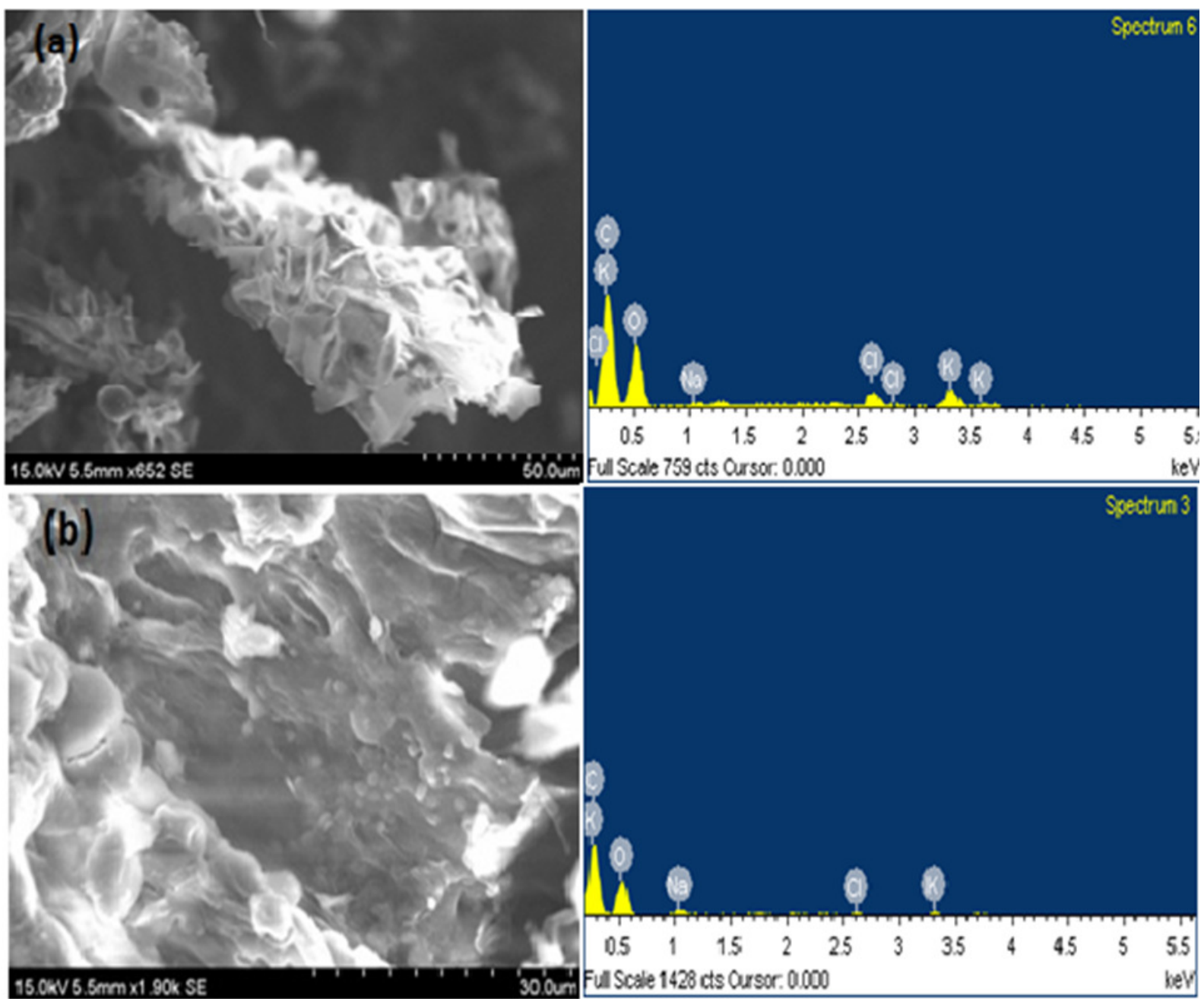

Fig. 3. SEM image and corresponding EDAX spectra of water clover (a) before adsorption (b) after adsorption 


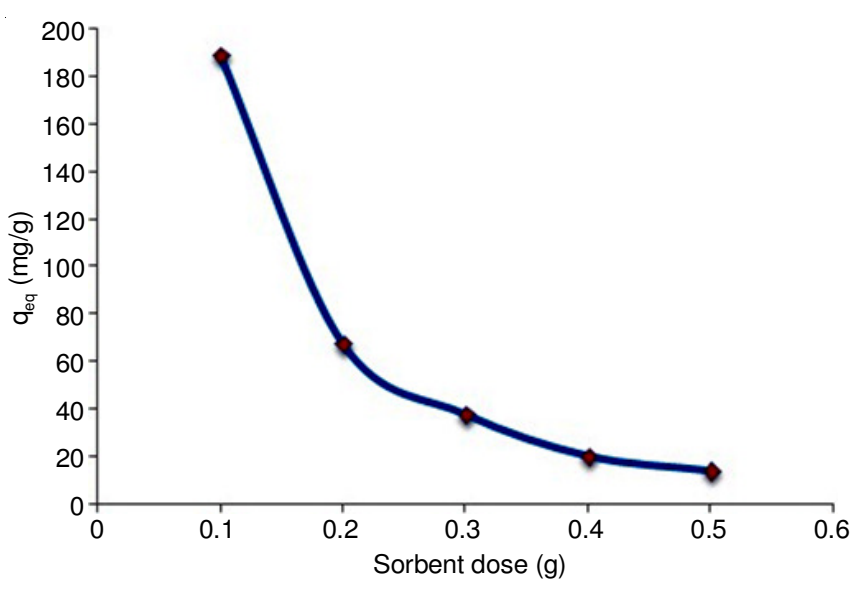

Fig. 4. Effect of adsorbent dosage on biosorption of procion blue H-5R using water clover (Initial dye conc.: $50 \mathrm{mg} / \mathrm{L}$, Agitation rate: 180 rpm, pH: solution $\mathrm{pH}$ )

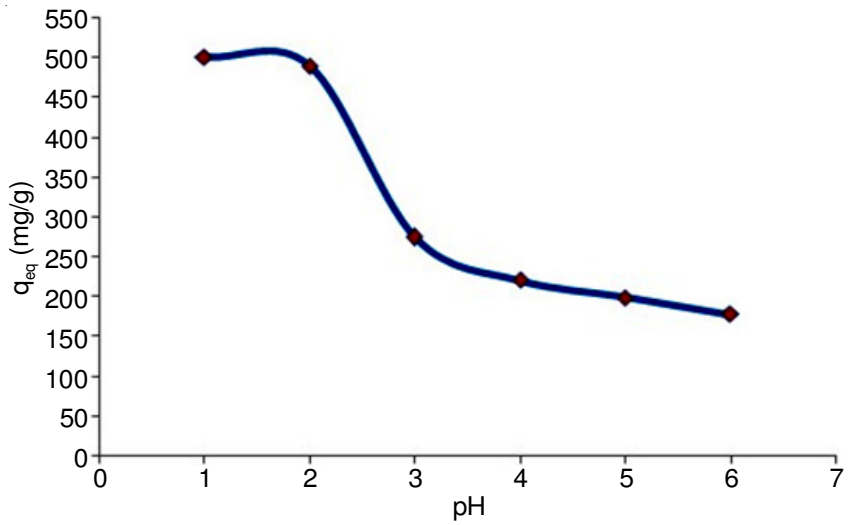

Fig. 5. Effect of $\mathrm{pH}$ on biosorption of procion blue $\mathrm{H}-5 \mathrm{R}$ using water clover (Initial dye conc.: $50 \mathrm{mg} / \mathrm{L}$, Agitation rate: $180 \mathrm{rpm}$, biosorbent dose: $0.1 \mathrm{~g}$ )

Effect of initial concentration of dye solution: The effect of initial procion blue $\mathrm{H}-5 \mathrm{R}$ concentration on the procion blue H-5R adsorption by water clover is shown in Fig. 6. Dye concentration also affects the efficiency of colour removal. Initial concentration is a major factor contributing to the affinity between dye present in aqueous solution and the adsorbent in the solid phase. Hence a higher initial concentration of dye may enhance the process. Similar results were reported by various authors [27-29]. Fig. 6 shows that the contact time needed for procion blue H-5R solutions with initial concentrations of $25-50 \mathrm{mg} / \mathrm{L}$ to reach equilibrium was $30 \mathrm{~min}$. At higher concentrations, a longer period of upto $120 \mathrm{~min}$ was required for the attainment of equilibrium. The initial sharp rise in the extent of adsorption with increasing dye concentration is due to higher adsorption potential of the surface at the beginning whereas the bombarding solute molecules find it difficult to access the remaining vacant surface sites due to decrease in the adsorption potential of water clover surface with more and more sites being filled up. An increase in initial concentration of procion blue $\mathrm{H}-5 \mathrm{R}$ dye accelerated the diffusion of dye molecules from bulk solution onto water clover. It can also be seen that the uptake capacity of dye $(\mathrm{mg} / \mathrm{g})$ increased with increase in dye concentration from $25 \mathrm{mg} / \mathrm{L}$ to $200 \mathrm{mg} / \mathrm{L}$ and remained constant after equilibrium time.

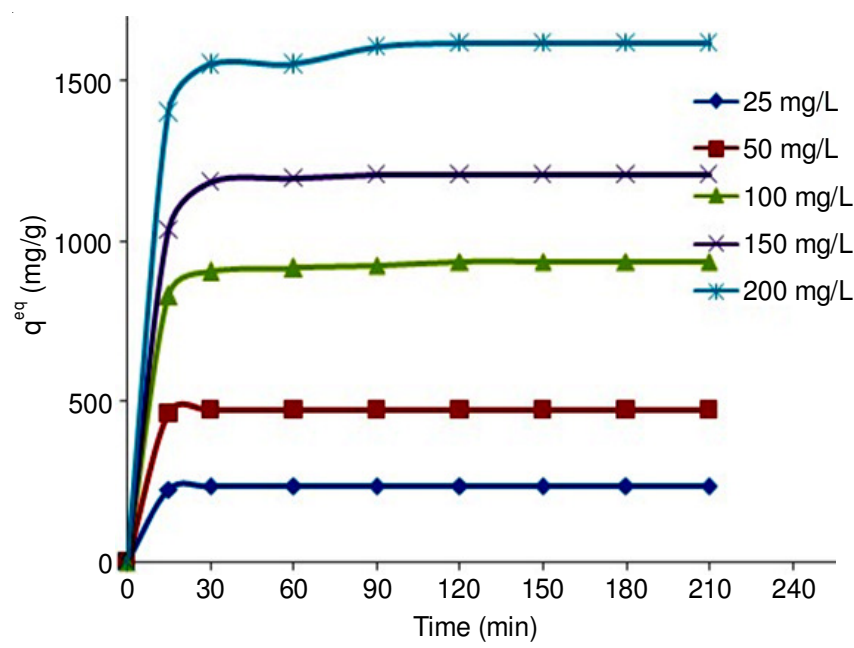

Fig. 6. Effect of initial dye concentration on the uptake capacity of procion blue H-5R using water clover at different time intervals (Biosorbent dosage: $0.1 \mathrm{~g}, \mathrm{pH}: 1$, Agitation rate: $180 \mathrm{rpm}$ )

Adsorption isotherm: To examine the relationship between adsorbent and adsorbate at equilibrium and to search for the maximum sorption capacity of adsorbent, Langmuir and Freundlich isotherms were applied. The Langmuir adsorption model is proposed on the postulation that the maximum adsorption corresponds to the solute molecules which are like a saturated single layer adsorbed on the surface of the adsorbent and is represented by the following equation:

$$
\mathrm{q}_{\mathrm{eq}}=\frac{\mathrm{Q}^{\mathrm{o}} \mathrm{bC}_{\mathrm{eq}}}{1+\mathrm{bC}_{\mathrm{eq}}}
$$

Linearized form of Langmuir equation is:

$$
\frac{\mathrm{C}_{\mathrm{eq}}}{\mathrm{q}_{\mathrm{eq}}}=\frac{\mathrm{C}_{\mathrm{eq}}}{\mathrm{Q}^{\circ}}+\frac{1}{\mathrm{bQ}^{\circ}}
$$

where, $\mathrm{q}_{\mathrm{eq}}(\mathrm{mg} / \mathrm{g})$ and $\mathrm{C}_{\mathrm{eq}}(\mathrm{mg} / \mathrm{L})$ are the amount of dye biosorbed per unit weight of biomass and unbiosorbed dye concentration in solution at equilibrium, respectively. $\mathrm{Q}^{\circ}$ is the maximum amount of dye biosorbed per unit weight of biomass required to form a complete monolayer on the surface and $\mathrm{b}$ is a constant related to the affinity of the binding sites ( $\mathrm{L} / \mathrm{mg}$ ) [30]. The plot of $\mathrm{C}_{\mathrm{eq}} / \mathrm{q}_{\mathrm{eq}}$ versus $\mathrm{C}_{\mathrm{eq}}$ turns to be linear as shown in Fig. 7 and the correlation coefficient is 0.9656.The Langmuir constants $\mathrm{Q}^{\circ}$ and $\mathrm{b}$ were determined from the slope and intercept of the plot and are presented in Table-1.

The features of the Langmuir isotherm can be represented in terms of a separation factor $\mathrm{R}_{\mathrm{L}}$ which is dimensionless and is given by eqn. 5 :

TABLE-1

PARAMETER VALUES FROM FITTING THE ADSORPTION EQUILIBRIUM DATA WITH ISOTHERM MODELS

\begin{tabular}{ccc}
\hline \multicolumn{3}{c}{ Langmuir isotherm } \\
\hline $\mathrm{Q}^{\mathbf{0}}$ & 1666.6667 \\
$\mathrm{~b}$ & 0.2608 \\
$\mathrm{R}^{2}$ & 0.9656 \\
\hline \multicolumn{3}{c}{ Freundlich isotherm } \\
\hline $\mathrm{K}_{\mathrm{F}}$ & 168.8481 \\
$\mathrm{n}$ & 0.4954 \\
$\mathrm{R}^{2}$ & 0.8748 \\
\hline
\end{tabular}




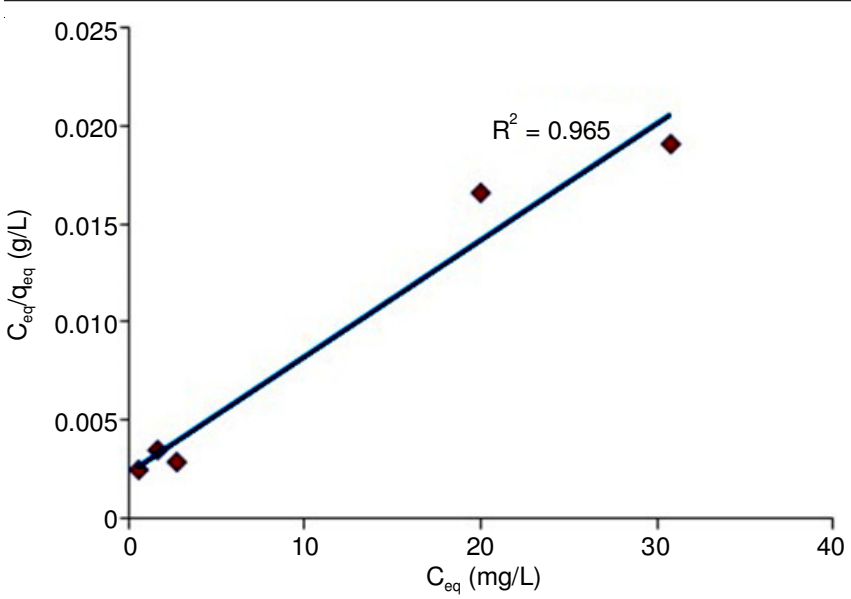

Fig. 7. Plot of Langmuir adsorption isotherm model for the biosorption of procion blue $\mathrm{H}-5 \mathrm{R}$ dye using water clover (biosorbent dosage: 0.1 $\mathrm{g}, \mathrm{pH}: 1$, agitation rate: $180 \mathrm{rpm}$ )

$$
\mathrm{R}_{\mathrm{L}}=\frac{1}{1+\mathrm{bC}_{0}}
$$

where $\mathrm{C}_{\mathrm{o}}$ is the initial concentration $(\mathrm{mg} / \mathrm{L})$ and $\mathrm{b}$ is the Langmuir constant $(\mathrm{L} / \mathrm{mg})$. The parameter $\mathrm{R}_{\mathrm{L}}$ denotes the type of adsorption process taking place between the sorbent and dye molecules. The relationship between the $\mathrm{R}_{\mathrm{L}}$ value and nature of adsorption is listed in Table-2.

\section{TABLE-2}

$\mathrm{R}_{\mathrm{L}}$ VALUES PREDICTING THE NATURE OF ADSORPTION

$\mathrm{R}_{\mathrm{L}}>1$
$0<\mathrm{R}_{\mathrm{L}}<1$
$\mathrm{R}_{\mathrm{L}}=0$
$\mathrm{R}_{\mathrm{L}}=1$

Unfavourable adsorption Favourable adsorption Irreversible adsorption Linear adsorption

The value of $\mathrm{R}_{\mathrm{L}}$ in the present investigation has been found to be 0.07257 showing that the adsorption of procion blue $\mathrm{H}-5 \mathrm{R}$ on water clover is favourable.

The Freundlich adsorption model is based on non-ideal sorption that is based on the assumption of heterogeneous surface energy systems and is given by the following equation:

$$
\mathrm{q}_{\mathrm{eq}}=\mathrm{K}_{\mathrm{F}} \mathrm{C}_{\mathrm{eq}}^{1 / \mathrm{n}}
$$

Linearized form of Freundlich equation is:

$$
\log \mathrm{q}_{\mathrm{eq}}=\log \mathrm{K}_{\mathrm{F}}+\frac{1}{\mathrm{n}} \log \mathrm{C}_{\mathrm{eq}}
$$

where, $\mathrm{q}_{\mathrm{eq}}(\mathrm{mg} / \mathrm{g})$ and $\mathrm{C}_{\mathrm{eq}}(\mathrm{mg} / \mathrm{L})$ are the amount of dye biosorbed per unit weight of biomass and unbiosorbed dye concentration in solution at equilibrium respectively [31]. $\mathrm{K}_{\mathrm{F}}$ is the biosorption capacity and $\mathrm{n}$ is the biosorption intensity. The plot of $\log \mathrm{C}_{\mathrm{eq}}$ versus $\log \mathrm{Q}_{\mathrm{eq}}$ is linear with correlation coefficient, $R^{2}=0.8748$, which is shown in Fig. 8. Values of $\mathrm{K}_{\mathrm{F}}$ and $\mathrm{n}$ are calculated from the intercept and slope of the plot and are listed in Table-1. The correlation coefficient, $\mathrm{R}^{2}$ value for Freundlich isotherm is lower than the $\mathrm{R}^{2}$ value of Langmuir isotherm, which confirms the monolayer coverage of procion blue $\mathrm{H}-5 \mathrm{R}$ onto water clover.

Adsorption kinetics: Pseudo first-order and second-order models were applied to test the experimental data and the kinetic adsorption process is elucidated. The pseudo-first order

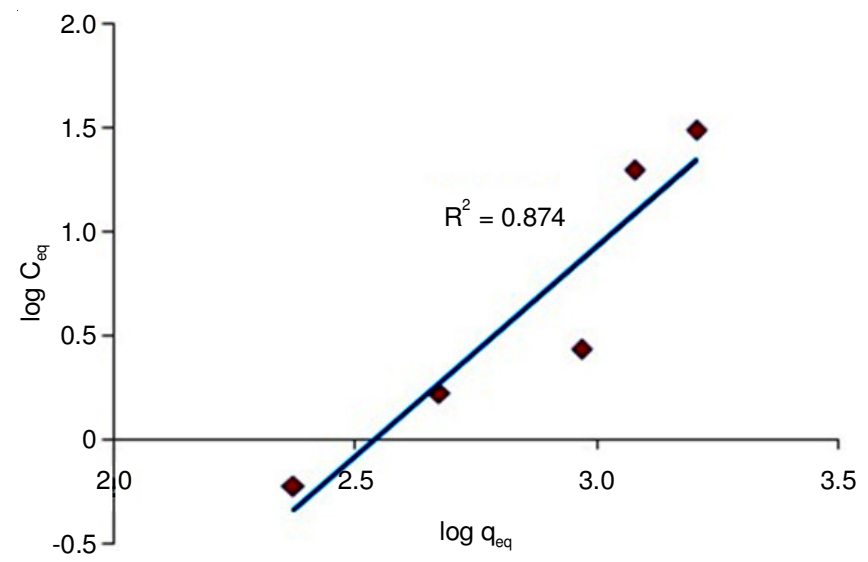

Fig. 8. Plot of Freundlich adsorption isotherm model for the biosorption of procion blue $\mathrm{H}-5 \mathrm{R}$ dye using water clover (biosorbent dosage: $0.1 \mathrm{~g}, \mathrm{pH}: 1$, agitation rate: $180 \mathrm{rpm})$

model proposed by Lagergren [32] can be applied for adsorption of solutes from a liquid. The pseudo-first order rate equation is:

$$
\frac{\mathrm{dq}}{\mathrm{dt}}=\mathrm{k}_{1}\left(\mathrm{q}_{\mathrm{eq}}-\mathrm{q}_{\mathrm{t}}\right)
$$

The integrated form of eqn. 4 is:

$$
\log \left(\mathrm{q}_{\mathrm{eq}}-\mathrm{q}_{\mathrm{t}}\right)=\log \mathrm{q}_{\mathrm{eq}}-\frac{\mathrm{k}_{1}}{2.303} \mathrm{t}
$$

where $\mathrm{q}_{\mathrm{t}}(\mathrm{mg} / \mathrm{g})$ and $\mathrm{q}_{\mathrm{eq}}(\mathrm{mg} / \mathrm{g})$ are milligrams of dye adsorbed per gram of adsorbent at a given time and equilibrium respectively and $\mathrm{k}_{1}$ is the rate constant $\left(\mathrm{min}^{-1}\right)$ of first order adsorption. The plot of $\log \left(\mathrm{q}_{\mathrm{eq}}-\mathrm{q}\right)$ against time, gives a straight line as shown in Fig. 9. $\mathrm{k}_{1}$ and $\mathrm{q}_{\mathrm{eq}}$ can be determined from the slope and intercept of the plot respectively, which is presented in Table-3.

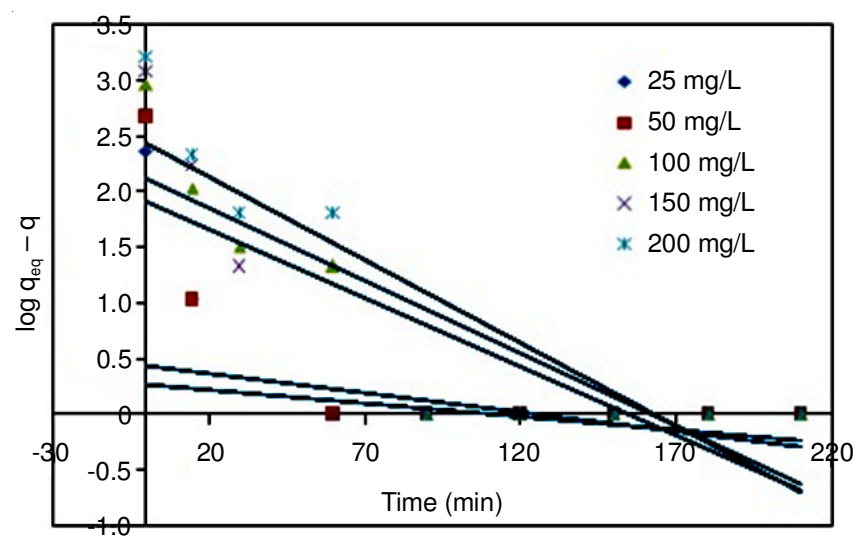

Fig. 9. Pseudo-first order plot for the biosorption of procion blue H-5R using water clover biomass

The pseudo-second-order kinetic model was used to study the adsorption kinetics of the present system. The pseudosecond order model [33] is based on the assumption that the adsorption capacity is proportional to the number of active sites occupied on the adsorbent and can be written as follows:

$$
\frac{\mathrm{dq}_{\mathrm{t}}}{\mathrm{dt}}=\mathrm{k}_{2}\left(\mathrm{q}_{\mathrm{eq}}-\mathrm{q}_{\mathrm{t}}\right)^{2}
$$

The integrated form of eqn. 10 is: 
TABLE-3

KINETIC MODEL VALUES FOR ADSOPTION OF PROCION BLUE H-5R ONTO WATER CLOVER

\begin{tabular}{ccccc|ccc}
\hline \multirow{2}{*}{$\mathrm{C}_{0}(\mathrm{mg} / \mathrm{L})$} & \multirow{2}{*}{$\mathrm{q}_{\text {eq,exp }}(\mathrm{mg} / \mathrm{g})$} & \multicolumn{3}{c|}{ Pseudo-first-order kinetic model } & \multicolumn{3}{c}{ Pseudo-second-order kinetic model } \\
\cline { 3 - 8 } & & $\mathrm{q}_{\text {eq, calc }}(\mathrm{mg} / \mathrm{g})$ & $\mathrm{k}_{1}\left(\mathrm{~min}^{-1}\right)$ & $\mathrm{R}^{2}$ & $\mathrm{q}_{\text {eq, calc }}(\mathrm{mg} / \mathrm{g})$ & $\mathrm{k}_{2}(\mathrm{~g} / \mathrm{mg} \min )$ & $\mathrm{R}^{2}$ \\
\hline 25 & 236.56 & 1.85 & 0.0055 & 0.0164 & 238.10 & 0.0220 & 1 \\
50 & 473.12 & 2.73 & 0.0081 & 0.0347 & 476.19 & 0.0220 & 1 \\
100 & 935.48 & 130.62 & 0.0302 & 0.7593 & 909.09 & 0.0009 & 0.9999 \\
150 & 1204.30 & 82.62 & 0.0285 & 0.6098 & 1250.00 & 0.0008 & 0.9999 \\
200 & 1612.90 & 273.53 & 0.0343 & 0.7751 & 1562.50 & 0.0004 & 0.9999 \\
\hline
\end{tabular}

$$
\frac{\mathrm{t}}{\mathrm{q}_{\mathrm{t}}}=\frac{1}{\mathrm{k}_{2} \mathrm{q}_{\mathrm{eq}}^{2}}-\frac{1}{\mathrm{q}_{\mathrm{eq}}} \mathrm{t}
$$

where $\mathrm{q}_{\mathrm{t}}(\mathrm{mg} / \mathrm{g})$ and $\mathrm{q}_{\mathrm{eq}}(\mathrm{mg} / \mathrm{g})$ are milligrams of dye adsorbed per gram of adsorbent at a given time $(\mathrm{t})$ and equilibrium respectively and $\mathrm{k}_{2}$ is the rate constant $\left(\mathrm{min}^{-1}\right)$ of second order adsorption. The plot of $\mathrm{t} / \mathrm{q}$ against $\mathrm{t}$, gives a straight line as shown in Fig. 10; $\mathrm{k}_{2}$ and $\mathrm{q}_{\mathrm{eq}}$ can be determined from the slope and intercept of the plot. $\mathrm{k}_{2}, \mathrm{q}_{\mathrm{eq}}$ and correlation coefficient $\mathrm{R}^{2}$ are presented in Table- 3 . The good agreement between calculated and experimental $\mathrm{q}_{\mathrm{eq}}$ values, high correlation coefficients and linear nature of plot of $\mathrm{t} / \mathrm{q}$ versus time confirms that the adsorption data are represented by the pseudo-second order kinetics. Fig. 11 clearly shows the calculated and experimental equilibrium dye uptake values for the biosorption of procion blue H-5R at different initial dye concentrations onto water clover.

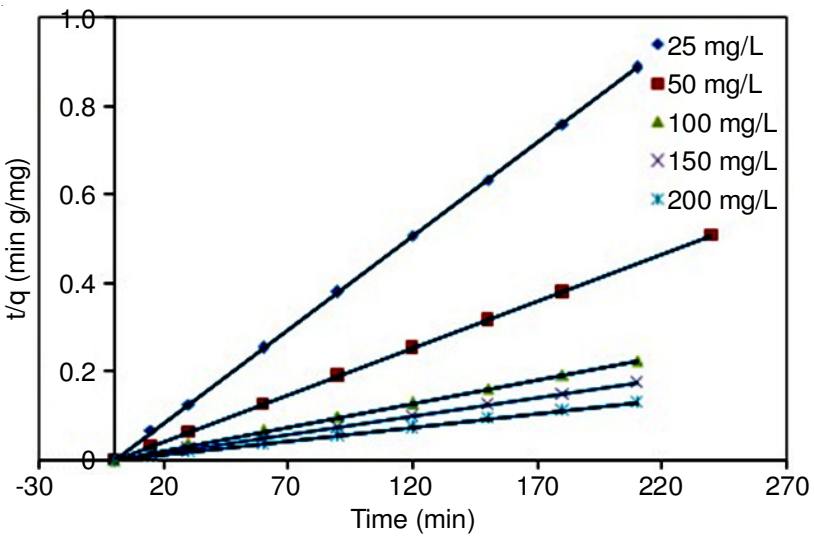

Fig. 10. Pseudo-second order plot for the biosorption of procion blue H-5R using water clover biomass

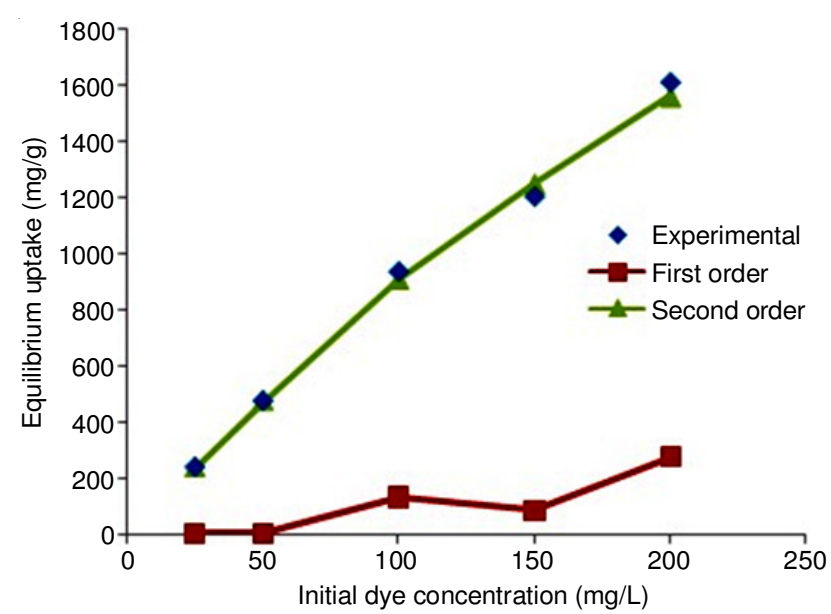

Fig. 11. The calculated and experimental equilibrium dye uptake values for the biosorption of procion blue H-5R at different initial dye concentrations using water clover

\section{Conclusion}

The results revealed the potential of water clover as an effective, biodegradable and low-cost biosorbent for removal of procion blue H-5R dye. The following conclusions were arrived:

- The adsorption capacities of procion blue H-5R dye increases with initial concentration and decreases with $\mathrm{pH}$ and adsorbent dosage.

- The Langmuir isotherm best described the equilibrium data with $\mathrm{R}^{2}=0.9656$, which signifies that homogeneous adsorption takes place between procion blue H-5R dye and water clover.

- Adsorption kinetics of procion blue H-5R removal by water clover follows pseudo-second-order model. The values of $\mathrm{q}_{\mathrm{eq}}$ calculated from pseudo-second-order plots are in good agreement with the experimental values. The $\mathrm{R}^{2}$ values ranges between 0.9999-1.0.

- FT-IR data confirms the procion blue H-5R adsorption onto water clover by the decrease in peak intensities for water clover upon adsorption of procion blue H-5R.

- SEM analysis reveals that the morphology of water clover is porous and highly favours adsorption of procion blue $\mathrm{H}-5 \mathrm{R}$ dye. The after adsorption micrograph shows procion blue H-5R molecules adsorbed on the surface of water clover.

\section{REFERENCES}

1. A.N. Ejhieh and M. Khorsandi, J. Hazard. Mater., 176, 629 (2010); https://doi.org/10.1016/j.jhazmat.2009.11.077.

2. S.R. Popuri, Y. Vijaya, V.M. Boddu and K. Abburi, Bioresour. Technol., 100, 194 (2009); https://doi.org/10.1016/j.biortech.2008.05.041.

3. J. Acharya, J.N. Sahu, B.K. Sahoo, C.R. Mohanty and B.C. Meikap, Chem. Eng. J., 150, 25 (2009); https://doi.org/10.1016/j.cej.2008.11.035.

4. C. Ozer, M. Imamoglu, Y. Turhan and F. Boysan, Toxicol. Environ. Chem., 94, 1283 (2012); https://doi.org/10.1080/02772248.2012.707656.

5. M. Imamoglu, J. Dispers. Sci. Technol., 34, 1183 (2013); https://doi.org/10.1080/01932691.2012.739869.

6. W.T. Tsai, C.Y. Chang, M.C. Lin, S.F. Chien, H.F. Sun and M.F. Hsieh, Chemosphere, 45, 51 (2001); https://doi.org/10.1016/S0045-6535(01)00016-9.

7. C. Namasivayam and D. Kavitha, Dyes Pigments, 54, 47 (2002); https://doi.org/10.1016/S0143-7208(02)00025-6.

8. R. Sivaraj, C. Namasivayam and K. Kadirvelu, Waste Manag., 21, 105 (2001); https://doi.org/10.1016/S0956-053X(00)00076-3.

9. M.K.B. Gratuito, T. Panyathanmaporn, R.-A. Chumnanklang, N. Sirinuntawittaya and A. Dutta, Bioresour. Technol., 99, 4887 (2008); https://doi.org/10.1016/j.biortech.2007.09.042.

10. W. Li, L. Zhang, J. Peng, N. Li and X. Zhu, Ind. Crops Prod., 27, 341 (2008); https://doi.org/10.1016/j.indcrop.2007.11.011 
11. S. Jemimah, In Proceedings of International Conference on Water Conservation - Save Blue to Save Green, Anna Adarsh College for Women, Chennai, India, pp. 59-63 (2015).

12. K.S. Bharathi and S.T. Ramesh, Appl. Water Sci, , 3, 773 (2013); https://doi.org/10.1007/s13201-013-0117-y.

13. A.A. Adeyemo, I.O. Adeoye and O.S. Bello, Appl. Water Sci., 20, 1 (2015); https://doi.org/10.1007/s13201-015-0322-y.

14. S. Sharma, J. Kaushal and P. Mahajan, Int. J. Adv. Res. Technol., 4, 143 (2016).

15. S. Jemimah and S.R. Bheeter, Asian J. Chem., 29, 535 (2017); https://doi.org/10.14233/ajchem.2017.20225

16. I. Gudelj, J. Hrenoviæ, T.L. Dragièevic, F. Delas, V. Soljan and H. Gudelj, Arh. Hig. Rada Toksikol., 62, 91 (2011); https://doi.org/10.2478/10004-1254-62-2011-2063.

17. G.F. Huang, Q.T. Wu, J.W.C. Wong and B.B. Nagar, Bioresour. Technol., 97, 1834 (2006); https://doi.org/10.1016/j.biortech.2005.08.024.

18. S. Renganathan, P. Gautam, V. Karthik, L.R. Miranda and M. Velan, Asia-Pac. J. Chem. Eng., 3, 400 (2008); https://doi.org/10.1002/apj.140.

19. G. Saranya, P. Saravanan, M. Dharmendira Kumar and S. Renganathan, Clean-Soil, Air Water, 39, 283 (2011); https://doi.org/10.1002/clen.201000186.

20. M.A.M. Salleh, D.K. Mahmoud, W.A.W.A. Karim and A. Idris, Desalination, 280, 1 (2011); https://doi.org/10.1016/j.desal.2011.07.019.

21. G.M. Ratnamala and K. Brajesh, Int. J. Environ. Sci. Technol., 2, 80 (2013).
22. G. Annadurai, R. Juang and D. Lee, J. Hazard. Mater., 92, 263 (2002); https://doi.org/10.1016/S0304-3894(02)00017-1.

23. I.D. Mall, V.C. Srivastava, N.K. Agarwal and I.M. Mishra, Colloids Surf. A Physicochem. Eng. Asp., 264, 17 (2005); https://doi.org/10.1016/j.colsurfa.2005.03.027.

24. I.D. Mall, V.C. Srivastava and N.K. Agarwal, Dyes Pigments, 69, 210 (2006); https://doi.org/10.1016/j.dyepig.2005.03.013.

25. G. Newcombe and M. Drikas, Carbon, 35, 1239 (1997); https://doi.org/10.1016/S0008-6223(97)00078-X.

26. J.M. Gómez, J. Galán, A. Rodríguez and G.M. Walker, J. Environ. Manage., 146, 355 (2014); https://doi.org/10.1016/j.jenvman.2014.07.041.

27. L.S. Oliveira, A.S. Franca, T.M. Alves and S.D.F. Rocha, J. Hazard. Mater, 155, 507 (2008); https://doi.org/10.1016/j.jhazmat.2007.11.093.

28. M. Arami, N. Limaee and N. Mahmoodi, Chem. Eng. J., 139, 2 (2008); https://doi.org/10.1016/j.cej.2007.07.060

29. H. Lata, S. Mor, V.K. Garg and R.K. Gupta, J. Hazard. Mater., 153, 213 (2008); https://doi.org/10.1016/i.jhazmat.2007.08.039.

30. I. Langmuir, J. Am. Chem. Soc., 40, 1361 (1918); https://doi.org/10.1021/ja02242a004.

31. H. Freundlich, J. Phys. Chem., 57, 385 (1907).

32. S. Lagergren, K. Sven. Vetensk. Akad. Handl., 24, 1 (1898).

33. Y.S. Ho and G. McKay, Process Biochem., 34, 451 (1999); https://doi.org/10.1016/S0032-9592(98)00112-5. 